\title{
Determinación del efecto del estrés inducido por la influencia de un depredador (Felis silvestris, sub especie catus - gato doméstico) sobre el tejido cardiaco, cerebro y células del sistema inmune en especímenes machos de Rattus novergicus var. Sprague dawley.
}

Determination of the effect of stress induced by the influence of a predator (Felis silvestris, sub species catus - domestic cat) on the cardiac tissue, brain and cells of the immune system in male species of Rattus novergicus var. Sprague dawley.

Jackeline Zaida Cusirramos Chahua y Henry Diaz-Murillo.

Universidad Nacional de San Agustín. Arequipa Perú.

\section{INFORMACIÓN}

\section{Historia del Artículo}

Recepción: 28/03/2019

Revisión: 14/05/2019

Aceptación: 18/05/2019

\section{Palabras Clave}

Estrés, cerebro, corazón, Rattus novergicus variedad Sprague Dawley, globulos blancos.

\section{Key Words}

Stress, brain, heart, Rattus novergicus variety Sprague Dawley, white blood cells.

\section{DOI}

https://doi.org/10.35286/veritas. v20i2.251

\begin{abstract}
RESUMEN
Se evaluó los efectos del estrés sobre los niveles de TGO (Transaminasa Glutámico Oxalacética), fórmula leucocitaria y cambios histológico en cerebro y corazón de Rattus novergicus variedad Sprague Dawley. La evaluación experimental se realizó en el Laboratorio de Fisiología Animal del Departamento Académico de Biología de la U.N.S.A.-Arequipa, durante los meses de noviembre 2015 a enero del 2016. Se utilizaron 24 Rattus novergicus variedad Sprague Dawley asignados en cuatro grupos: T1 (grupo control, alejadas de cualquier estimulo que les perturbe), T2 (presencia de depredadores por $20 \mathrm{~min}$./día/ciclo diurno), T3 (presencia de depredadores por $20 \mathrm{~min} . /$ día/ciclo noche), T4 (presencia de depredadores por $20 \mathrm{~min} . / \mathrm{cada} 7 \mathrm{días} / \mathrm{ciclo}$ diurno), durante 4 semanas. Se demostró que el estrés provoca un incremento estadísticamente significativo en los niveles de TGO en sangre de las ratas, con respecto a los niveles basales, pero no existe una diferencia significativa entre los tratamientos. Se demostró que el estrés afecta las cantidades basales de la fórmula leucocitaria, encontrando un aumento estadísticamente significativo en la cantidad de monocitos circulantes, un aumento en promedios (aunque no estadísticamente significativo) de Eosinófilos circulantes, una disminución en promedios (aunque no estadísticamente significativo) de linfocitos, una disminución estadísticamente significativa de la cantidad de neutrófilos bandeados; todos estos niveles en promedios con valores limites en el T3. La cantidad de Basófilos permaneció indiferente al efecto del estrés. La cantidad de neutrófilos segmentados evidenciaron una disminución en promedios (aunque no estadísticamente significativo) en el T4. Se demostró que el estrés provoca daño en los tejidos nervioso (edema y congestión vascular) y cardiaco (congestión vascular). Siendo más severa la inflamación cerebral en el T3 y T4, mientras que el daño en el tejido cardiaco fue similar en los tratamientos $\mathrm{T} 2, \mathrm{~T} 3$ y $\mathrm{T} 4$.
\end{abstract}

\begin{abstract}
The effects of stress on the levels of TGO (Glutamic Oxalacetic Transaminase), leukocyte formula and histological changes in brain and heart of Rattus novergicus variety Sprague Dawley variety were evaluated. The experimental evaluation was carried out in the Laboratory of Animal Physiology of the Academic Department of Biology of the UNSA-Arequipa, during the months of November 2015 to January 2016. 24 Rattus novergicus Sprague Dawley variety assigned in four groups were used: T1 (control group, away from any stimulus that disturbs them), T2 (presence of predators for $20 \mathrm{~min}$./day/day cycle), T3 (presence of predators for 20 min./day / night cycle), T4 (presence of predators for 20 min ./every 7 days / day cycle), for 4 weeks. It was shown that stress causes a statistically significant increase in blood TGO levels in rats, compared to baseline levels, but there is no significant difference between treatments.It was shown that stress affects the basal amounts of the leukocyte formula, finding a statistically significant increase in the amount of circulating monocytes, an increase in averages (although not statistically significant) of circulating Eosinophils, a decrease in averages (although not statistically significant) of Lymphocytes, a statistically significant decrease in the amount of Banded Neutrophils; all these levels in averages with limit values in T3. The amount of Basophils remained indifferent to the effect of stress. The number of Segmented Neutrophils showed a decrease in averages (although not statistically significant) in T4. Stress was shown to cause damage to nervous (edema and vascular congestion) and cardiac (vascular congestion) tissues. Brain swelling was more severe in $\mathrm{T} 3$ and $\mathrm{T} 4$, while damage to cardiac tissue was similar in treatments $\mathrm{T} 2, \mathrm{~T} 3$ and $\mathrm{T} 4$.
\end{abstract}




\section{INTRODUCCIÓN}

El estrés es la respuesta fisiológica a alguna perturbación de origen interno o externo, que altera el equilibrio de los sistemas metabólicos celulares, provocando respuestas adaptativas.

La exposición al estrés en los seres vivos se produce generalmente por una perturbación de las condiciones medioambientales que inducen una reacción a niveles molecular, bioquímico, celular, tisular, orgánico y sistémico; dicha reacción es adaptativa, lo que significa que permite al individuo balancear su equilibrio al ritmo del ambiente para no morir. Esta perturbación tiene un tiempo normal de duración hasta que el organismo encuentra las vías para restablecer su equilibrio interno después de haber generado una respuesta adaptativa de supervivencia.

Sin embargo, cuando la fuente de estrés es continua y el organismo no logra restablecer su equilibrio, recae en un agotamiento a distintos niveles, los sistemas metabólicos se saturan, desequilibrando la función celular y en consecuencia evidenciando daño tisular y un desbalance orgánico general.

Esta perturbación tiene fuertes impactos celulares en los principales sistemas orgánicos, viéndose afectados el tejido nervioso, el tejido cardiaco y las células blancas del tejido sanguíneo, debido principalmente a que se integran en todo el organismo.

Actualmente la población está más expuesta a factores estresantes que en otras épocas de la historia de la humanidad, según la OMS (Leka, 2004, OMS) sobre salud ocupacional, son las condiciones de trabajo modernas las que han impactado fuertemente en la proliferación de enfermedades en la población económicamente activa, debido al estrés intrínseco asociado al mismo, traducido en la presión personal a nivel psicológico que sufre el individuo.

Se ha determinado que el estrés provoca una mayor predisposición a sufrir enfermedades ocasionadas por patógenos y cardiovasculares, a experimentar cansancio y agotamiento físico exagerado, y a disminuir sus niveles de atención y memoria.

Actualmente el estudio de los efectos del estrés se centra en los impactos psicológicos en el individuo y metodologías para combatirlos, pero poco se ha estudiado sobre sus efectos a nivel orgánico y menos a nivel tisular, debido a que el seguimiento de los efectos de un tipo de estrés es inexacto cuando se trata de asociarlo a una patología determinada en seres humanos.

Aunque el estrés ha sido señalado como una de las principales causas de las patologías psicosomáticas, cardiovasculares, neurológicas, inmunológicas y sistémicas, aún no se conoce exactamente que vías son las que intervienen y como se relacionan entre ellas, aunque las actuales líneas de investigación empiezan a hacer las conexiones entre los diferentes sistemas afectados y el sistema nervioso (central como periférico), falta mucha más información para poder entender como funciona estos mecanismos que terminan dañando el organismo.

\section{MATERIAL Y MÉTODOS}

\section{Lugar y fecha de ejecución}

El presente trabajo de investigación se realizó en el Laboratorio del Área de Fisiología Animal del Departamento Académico de Biología - U.N.S.A. durante el periodo de noviembre del 2015 a enero del 2016.

\section{Diseño Experimental}

\begin{tabular}{cc}
\hline TRATAMIENTO & N $^{\circ}$ DE RATAS \\
\hline T1 Control & 6 \\
$\begin{array}{c}\text { T2 sesiones de estrés provocada por } \\
\text { presencia de depredadores } 20 \mathrm{~min} / \\
\text { día/ciclo luz (entre las } 0800 \text { y } 1500 \\
\text { hs) } / 4 \text { sem. }\end{array}$ & 6 \\
T3 sesiones de estrés provocada por \\
presencia de depredadores 20 min/ \\
día/ciclo oscuridad (entre las 1900 y \\
0200 hs)/4 sem. \\
$\begin{array}{c}\text { T4 sesiones de estrés provocada por } \\
\text { presencia de depredadores } 20 \text { min/ } \\
\text { sem/ciclo día (entre las } 0800 \text { y } 1500 \\
\text { hs)/4 sem. }\end{array}$ \\
TOTAL \\
\hline
\end{tabular}

Los tratamientos se administraron por treinta días de acuerdo al diseño experimental descrito.

\section{Material y metodología}

Se utilizaron 24 individuos de la especie Rattus novergicus variedad Sprague Dawley, las que fueron alimentadas y sometidas por 30 días a estrés usando la presencia de depredador natural (Felis silvestris sub especie catus -gato doméstico -2 individuos hembras) con exposiciones diarias y/o semanales de 20 minutos/ciclo día (entre las 0800 y $1500 \mathrm{hs}$ ) y de 20 minutos/ciclo nocturno (entre las $1900 \mathrm{y}$ 0200 hs); para esto se utilizó una canastilla rectangular de $10 \times 10 \times 20 \mathrm{~cm}$ donde eran metidas las ratas individualmente y puestas en una habitación limpia donde se soltaba los dos depredadores par que exploren libremente.

Cada 7 días se evaluaron los niveles de TGO y la formula leucocitaria. Se tomó muestras de sangre extraídas de la cola de las ratas de experimentación con la ayuda de una hoja de bisturí y un tubo capilar heparinizado; se procedió a centrifugar los capilares, debidamente rotulados, para obtener suero y utilizarlo para el examen de TGO, a la par se realizaban los frotis de sangre fresca en laminas porta objetos, según la metodología para luego ser teñidas con colorante Wright, lo que se realizó cada 7 días.

Al finalizar el periodo de experimentación, las ratas fueron sacrificadas para obtener el corazón y cerebro para la evaluación histológica; los que fueron preservados en frascos con formol al $10 \%$ debidamente rotulado para cada tratamiento. 
VÉRITAS Vol. 20 N² (2019) 105-116

\section{Determinacion de TGO (Transaminasa Glutámico Oxalacética}

\section{Fundamento del método}

La TGO (EC 2.6.1.1) cataliza la reacción de transferencia de un grupo amino desde el L-aspartato al 2-oxoglutarato formándose L-glutamato y oxalacetato. Esta enzima utiliza el piridoxal 5'-fosfato como cofactor. El piruvato formado (el oxalacetato es inestable y se transforma en piruvato), reacciona con la 2,4-dinitrofenilhidracina produciéndose, en medio alcalino, un compuesto coloreado, de modo que el aumento de la absorbancia leído a $505 \mathrm{~nm}$ es proporcional a la actividad Transaminasa Glutámico Oxalacética y la temperatura de reacción de la muestra.

\section{Reactivos provistos}

Reactivo A: solución con $100 \mathrm{mM}$ de 1 -aspartato y $2 \mathrm{mM}$ de $\alpha$-cetoglutarato en buffer fosfatos $100 \mathrm{mM}, \mathrm{pH} 7,4$.

Reactivo B: solución conteniendo $1 \mathrm{mmol}$ de 2,4-dinitrofenilhidracina (2,4-DNFH) en ácido clorhídrico 1 $\mathrm{mol} / \mathrm{l}$. C.

Reactivo C: solución de hidróxido de sodio $4 \mathrm{~mol} / \mathrm{l}$. S.

Standard: solución de piruvato de sodio $2 \mathrm{mmol} / \mathrm{l}$. Para efectuar la curva de calibración.

Concentraciones finales

Reactivo C diluido (0,40 mol/l); preparación: usar la cantidad de reactivo $\mathrm{C}$ y agua destilada en la proporción de 1:9, se preparó en la cantidad suficiente de acuerdo a la cantidad de muestras evaluadas.

\section{Muestra}

Suero

a. Recolección: se debe obtener suero de la manera usual. No es necesario que el paciente esté en ayunas para la extracción de sangre.

b. Aditivos: no se requieren.

c. Sustancias interferentes conocidas: los sueros hemolizados producen resultados falsamente elevados ya que los glóbulos rojos contienen 3 a 5 veces más enzimas que el suero.

d. Estabilidad e instrucciones de almacenamiento: en caso de no efectuarse la determinación en el día, puede conservarse el suero refrigerado a $4 \mathrm{o} \mathrm{C}$ durante no más de 5 días.

\section{Procedimiento}

Se arma una batería de tubos rotulados en una gradilla metálica en la cual se van a agregar de la siguiente forma los reactivos y las muestras de suero:

\begin{tabular}{ccc}
\hline Tipo de Reactivo & Blanco & Muestra \\
\hline Reactivo A & $0.1 \mathrm{ml}$ & $0.1 \mathrm{ml}$ \\
\hline
\end{tabular}

Se colocó en baño de agua a $37^{\circ} \mathrm{C} \pm 0,5^{\circ} \mathrm{C}$ unos minutos.

\begin{tabular}{ccc}
\hline Tipo de reactivo & Blanco & Muestra \\
\hline Suero & - & $20 \mathrm{uL}$ \\
Agua destilada & $20 \mathrm{uL}$ & - \\
\hline
\end{tabular}

Mezclar por agitación suave e incubar exactamente 30 minutos y agregar:

\begin{tabular}{ccc}
\hline Tipo de Reactivo & Blanco & Muestra \\
\hline Reactivo B & $0.1 \mathrm{ml}$ & $0.1 \mathrm{ml}$ \\
\hline
\end{tabular}

Mezclar. Dejar 10 minutos a 37o C. Luego agregar:

\begin{tabular}{rcc}
\hline Tipo de Reactivo & Blanco & Muestra \\
\hline Reactivo C diluido & $1 \mathrm{ml}$ & $1 \mathrm{ml}$ \\
\hline
\end{tabular}

Mezclar por inversión y retirar del baño. Después de 2 minutos leer la absorbancia en fotocolorímetro con filtro verde (500-550 nm); en espectrofotómetro a $505 \mathrm{~nm}$ o $\mathrm{Hg}$ 546, llevando el aparato a cero D.O. con agua destilada.

El color de la reacción es estable durante 30 minutos por lo que la absorbancia debe ser leída dentro de ese lapso.

\section{Cálculo de los resultados}

Se ha empleado las tablas de conversión provistas por el críptico del reactivo usado, el cálculo se basa en la absortividad del cromógeno y los valores de actividad enzimática pueden deducirse de las tablas de conversión obtenidas por comparación con el método UV convencional, siempre que las lecturas se efectúen en las siguientes condiciones de medida: cubetas de caras paralelas de $1 \mathrm{~cm}$ de espesor, semi ancho de banda $\leq 8 \mathrm{~nm}$ y longitud de onda 505 $\mathrm{nm}$ o Hg 546. GOT (30 min):

\begin{tabular}{ccc}
\hline Hg 546 & $\begin{array}{c}\text { Método UV convencional } \\
(\mathrm{U} / 1)\end{array}$ & $505 \mathrm{~nm}$ \\
\hline 0.020 & 5 & 0.034 \\
0.030 & 7 & 0.047 \\
0.040 & 10 & 0.061 \\
0.050 & 14 & 0.080 \\
0.060 & 19 & 0.100 \\
0.070 & 23 & 0.115 \\
0.080 & 26 & 0.129 \\
0.090 & 31 & 0.146 \\
0.100 & 36 & 0.164 \\
0.110 & 41 & 0.180 \\
0.120 & 46 & 0.196 \\
0.130 & 50 & 0.210 \\
0.140 & 55 & 0.224 \\
0.150 & 61 & 0.239 \\
0.160 & 67 & 0.254 \\
0.170 & 74 & 0.269 \\
\hline & &
\end{tabular}




\section{Evaluación histológica}

\section{Obtención de la muestra}

Después de sacrificado el animal, inmediatamente se procedió a extraer de ellos el corazón y el cerebro mediante disección, posteriormente se procedió a realizar el estudio histológico.

\section{Diagnóstico histopatológico}

El diagnóstico histopatológico de las muestras obtenidas se realizó en el Laboratorio de Anatomía Patológica del Hospital Carlos Alberto Seguín Escobedo ESSALUD por el Dr. Henry Mercado.

Para la evaluación histopatológico del corazón se utilizó la escala comparativa de daño que va desde:

Severa $(++++)$ : congestión vascular severa, edemas muy notorios, espacio intersticial muy amplio alrededor del vaso sanguíneo, presión sobre el tejido adyacente.

Moderada $(+++)$ : congestión vascular moderada, edemas notorios medianos, espacio intersticial mediano alrededor del vaso sanguíneo.

Leve $(++)$ : congestión vascular tipo edema poco notorios, espacio intersticial alrededor del vaso sanguíneo no genera mucha presión

Muy leve (+): edema casi imperceptible.

\section{Método estadístico}

Los datos se expresan como promedios. Las diferencias estadísticas entre los grupos fueron analizados por ANOVA y la prueba de especificidad de Tukey. Las diferencias fueron estadísticamente significativas si $\mathrm{p}<0.05$. Se utilizó el paquete estadístico computarizado SPSS versión 21.0 para Windows.

\section{RESULTADOS}

Se evaluó el efecto del estrés provocado por un depredador en Rattus novergicus variedad Sprague Dawley. Los resultados obtenidos se muestran en Tablas y Figuras.

Efecto del estrés sobre las concentraciones de TGO (Transaminasa Glutámico Oxalacético) de Rattus novergicus VARIEDAD SPRAGUE DAWLEY
Tabla 1: Transaminasa glutámico oxalacético (UI/L) de Rattus novergicus variedad Sprague Dawley sometidas a estrés durante 4 semanas

\begin{tabular}{|c|c|c|c|c|c|c|}
\hline \multirow{2}{*}{ TRATAMIENTO } & \multirow{2}{*}{$\mathrm{N}^{o}$} & \multicolumn{5}{|c|}{$\begin{array}{l}\text { TRANSAMINASA GLUTÁMICO OXALACÉTICO } \\
\text { UI/L }\end{array}$} \\
\hline & & BASAL & $\begin{array}{c}1 \mathrm{ra} \\
\text { semana }\end{array}$ & $\begin{array}{c}2 \mathrm{da} \\
\text { semana }\end{array}$ & $\begin{array}{c}\text { 3ra } \\
\text { semana }\end{array}$ & $\begin{array}{c}4 \text { ta } \\
\text { semana }\end{array}$ \\
\hline T1 CONTROL & 6 & 29.37 & 32.07 & 32.97 & 37.93 & 25.39 \\
\hline $\begin{array}{l}\text { T2 UNA VEZ } \\
\text { DIA/DIURNO }\end{array}$ & 6 & 28.32 & 127.91 & 98.77 & 70.68 & 87.2 \\
\hline $\begin{array}{l}\text { T3 UNA VEZ } \\
\text { DIA/NOCHE }\end{array}$ & 6 & 28.39 & 84.65 & 86.38 & 78.49 & 85.25 \\
\hline $\begin{array}{l}\text { T4 UNA VEZ/ } \\
\text { SEMANA }\end{array}$ & 6 & 36.2 & 145.34 & 135.47 & 78.34 & 87.2 \\
\hline F (ANOVA) & & 3.81 & \multirow{2}{*}{\multicolumn{4}{|c|}{$\begin{array}{c}0.03<0.05 \text { Se acepta la hipótesis alterna } \\
\text { que confirma que existe al menos un grupo } \\
\text { distinto del resto de los demás grupos }\end{array}$}} \\
\hline $\begin{array}{c}\mathrm{P} \\
\text { SIGNIFICANCIA }\end{array}$ & & $\begin{array}{l}0.03 \\
0.05\end{array}$ & & & & \\
\hline
\end{tabular}

En la Tabla 1 se muestra que si existe diferencia significativa $(p<0.05)$ entre los niveles de TGO (Transaminasa Glutámico Oxalacética) en sangre de las ratas en los diferentes tratamientos. Al aplicar la prueba de post comparación de Tukey se encontró que los niveles de TGO (Transaminasa Glutámico Oxalacética) del Grupo Control varían en sus niveles de manera significativa $(>0.05)$ en el tiempo, con respecto de los demás tratamientos, pero no existe diferencia significativa entre los tratamientos en el tiempo.

Tabla 2: Comparación de los promedios de los niveles de TGO (Transaminasa Glutámico Oxalacética) en sangre de Rattus novergicus variedad sprague dawley sometidas a estrés provocada por depredador durante 4 semanas

\begin{tabular}{ccccc}
\hline U/L & T1 & T2 & T3 & T4 \\
\hline BASAL & 29.37 & 28.32 & 28.39 & 36.2 \\
1RA SEMANA & 32.07 & 127.91 & 84.65 & 145.34 \\
2DA SEMANA & 32.97 & 98.77 & 86.38 & 135.47 \\
3RA SEMANA & 37.93 & 70.68 & 78.49 & 78.34 \\
4TA SEMANA & 25.39 & 87.2 & 85.25 & 87.2 \\
\hline
\end{tabular}

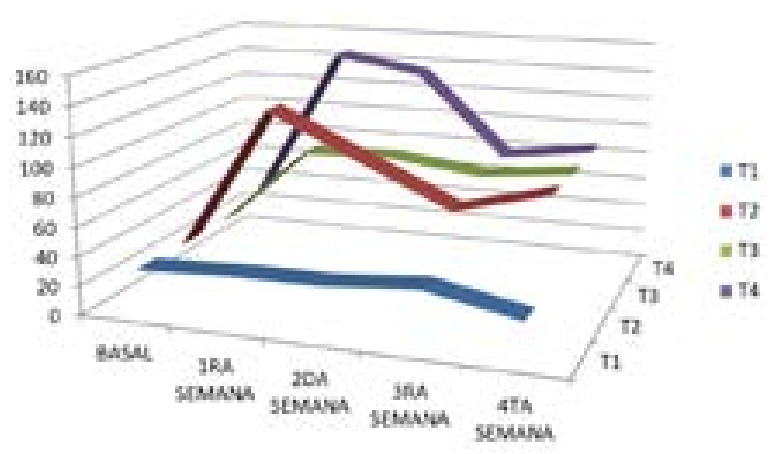

Gráfico 1: Comparación de los promedios de los niveles de TGO (Transaminasa Glutámico Oxalacética) en sangre de Rattus novergicus variedad Sprague Dawley sometidas a estrés provocada por depredador durante 4 semanas 
Efecto del estrés sobre la serie blanca del sistema inmunológico de Rattus Novergicus variedad Sprague Dawley

Tabla 3: Basófilos de la fórmula leucocitaria de Rattus Novergicus variedad Sprague Dawley sometidas a estrés provocada por depredador durante 4 semanas

\begin{tabular}{|c|c|c|c|c|c|c|}
\hline \multirow{2}{*}{ TRATAMIENTO } & \multirow{2}{*}{$\mathrm{N}^{\circ}$} & \multicolumn{5}{|c|}{$\begin{array}{l}\text { FÓRMULA LEUCOCITARIA } \\
\text { BASÓFILOS }\end{array}$} \\
\hline & & BASAL & 1ra semana & 2da seman & ra seman & ta semana \\
\hline T1 CONTROL & 6 & 0.0 & 0.0 & 0.0 & 0.0 & 0.0 \\
\hline $\begin{array}{l}\text { T2 UNA VEZ DÍA/ } \\
\text { DIURNO }\end{array}$ & 6 & 0.0 & 0.0 & 0.0 & 0.0 & 0.0 \\
\hline $\begin{array}{l}\text { T3 UNA VEZ DÍA/ } \\
\text { NOCHE }\end{array}$ & 6 & 0.0 & 0.3 & 0.0 & 0.0 & 0.0 \\
\hline $\begin{array}{l}\text { T4 UNA VEZ/ } \\
\text { SEMANA }\end{array}$ & 6 & 0.0 & 0.0 & 0.0 & 0.0 & 0.3 \\
\hline $\begin{array}{c}\text { F (ANOVA) } \\
\text { P } \\
\text { SIGNIFICANCIA }\end{array}$ & & & \multicolumn{4}{|c|}{$\begin{array}{l}\text { La incidencia de Basófilos en las } \\
\text { muestras basales fue casi nula en } \\
\text { promedio. }\end{array}$} \\
\hline
\end{tabular}

En la Tabla 2 se muestra de forma evidente que no existe diferencia significativa entre los basófilos de la formula leucocitaria de las ratas en los diferentes grupos de evaluación, debido a que la incidencia es baja.

Tabla 4: Eosinófilos de la fórmula leucocitaria de Rattus Novergicus variedad Sprague Dawley sometidas a estrés provocada por depredador durante 4 semanas

\begin{tabular}{|c|c|c|c|c|c|c|}
\hline \multirow{2}{*}{ TRATAMIENTO } & \multirow{2}{*}{$\mathrm{N}^{\circ}$} & \multicolumn{5}{|c|}{$\begin{array}{l}\text { FÓRMULA LEUCOCITARIA } \\
\text { EOSINÓFILOS }\end{array}$} \\
\hline & & BASAL & $\begin{array}{c}\text { 1ra } \\
\text { semana }\end{array}$ & $\begin{array}{c}2 \mathrm{da} \\
\text { semana }\end{array}$ & $\begin{array}{c}\text { 3ra } \\
\text { semana }\end{array}$ & $\begin{array}{c}4 \text { ta } \\
\text { semana }\end{array}$ \\
\hline T1 CONTROL & 6 & 0 & 0.33 & 0.3 & 0.7 & 0.3 \\
\hline $\begin{array}{l}\text { T2 UNA VEZ DÍA/ } \\
\text { DIURNO }\end{array}$ & 6 & 0 & 1.33 & 1.3 & 0 & 1.3 \\
\hline $\begin{array}{l}\text { T3 UNA VEZ DÍA/ } \\
\text { NOCHE }\end{array}$ & 6 & 0 & 1.33 & 6.3 & 0 & 4.3 \\
\hline $\begin{array}{l}\text { T4 UNA VEZ/ } \\
\text { SEMANA }\end{array}$ & 6 & 0 & 1.33 & 0.7 & 0.7 & 0.3 \\
\hline F (ANOVA) & & 1.97 & \multirow{2}{*}{\multicolumn{4}{|c|}{$\begin{array}{c}0.16>0.05 \text { Se acepta la hipótesis nula } \\
\text { que confirma que no existe diferencia } \\
\text { entre los grupos }\end{array}$}} \\
\hline $\begin{array}{c}\mathrm{P} \\
\text { SIGNIFICANCIA }\end{array}$ & & $\begin{array}{l}0.16 \\
0.05\end{array}$ & & & & \\
\hline
\end{tabular}

En la Tabla 3 se muestra que no existe diferencia significativa $(p<0.05)$ entre los Eosinófilos de fórmula leucocitaria de las ratas en los diferentes grupos de evaluación.
Tabla 5: Monocitos de la fórmula leucocitaria de Rattus Novergicus variedad Sprague Dawley sometidas a estrés provocada por depredador durante 4 semanas

\begin{tabular}{|c|c|c|c|c|c|c|}
\hline \multirow{2}{*}{ TRATAMIENTO } & \multirow{2}{*}{$\mathrm{N}^{\mathrm{o}}$} & \multicolumn{5}{|c|}{$\begin{array}{l}\text { FÓRMULA LEUCOCITARIA } \\
\text { MONOCITOS }\end{array}$} \\
\hline & & BASAL & $\begin{array}{c}\text { lra } \\
\text { semana }\end{array}$ & $\begin{array}{c}2 \mathrm{da} \\
\text { semana }\end{array}$ & $\begin{array}{c}\text { 3ra } \\
\text { semana }\end{array}$ & $\begin{array}{c}\text { 4ta } \\
\text { semana }\end{array}$ \\
\hline T1 CONTROL & 6 & 5.7 & 6.0 & 5.7 & 6.0 & 5.7 \\
\hline $\begin{array}{l}\text { T2 UNA VEZ DÍA/ } \\
\text { DIURNO }\end{array}$ & 6 & 4.3 & 18.3 & 47.3 & 42.7 & 34.0 \\
\hline $\begin{array}{l}\text { T3 UNA VEZ DÍA/ } \\
\text { NOCHE }\end{array}$ & 6 & 5.7 & 34.3 & 39.3 & 49.0 & 40.0 \\
\hline $\begin{array}{l}\text { T4 UNA VEZ/ } \\
\text { SEMANA }\end{array}$ & 6 & 5.3 & 27.7 & 35.3 & 20.7 & 43.3 \\
\hline F (ANOVA) & & 3.81 & \multirow{3}{*}{\multicolumn{4}{|c|}{$\begin{array}{c}0.03<0.05 \text { Se acepta la hipótesis } \\
\text { alterna que confirma que existe al } \\
\text { menos un grupo distinto del resto de } \\
\text { los demás grupos }\end{array}$}} \\
\hline $\mathrm{P}$ & & 0.03 & & & & \\
\hline SIGNIFICANCIA & & 0.05 & & & & \\
\hline
\end{tabular}

En la Tabla 4 se muestra que sí existe diferencia significativa $(p<0.05)$ entre los monocitos de la fórmula leucocitaria de las ratas en los diferentes tratamientos. Al aplicar la prueba de post comparación de Tukey se encontró que los Monocitos del grupo control varían sus cantidades de manera significativa $(>0.05)$ en el tiempo de los demás tratamientos, pero no existe diferencia significativa entre los tratamientos en el tiempo.

Tabla 6: Linfocitos de la fórmula leucocitaria de Rattus Novergicus variedad Sprague Dawley sometidas a estrés provocada por depredador durante 4 semanas

\begin{tabular}{|c|c|c|c|c|c|c|}
\hline \multirow{2}{*}{ TRATAMIENTO } & \multirow{2}{*}{$\mathrm{N}^{\circ}$} & \multicolumn{5}{|c|}{$\begin{array}{l}\text { FÓRMULA LEUCOCITARIA } \\
\text { LINFOCITOS }\end{array}$} \\
\hline & & BASAL & $\begin{array}{c}\text { 1ra } \\
\text { semana }\end{array}$ & $\begin{array}{c}2 \mathrm{da} \\
\text { semana }\end{array}$ & $\begin{array}{c}\text { 3ra } \\
\text { semana }\end{array}$ & $\begin{array}{c}\text { 4ta } \\
\text { semana }\end{array}$ \\
\hline T1 CONTROL & 6 & 41.3 & 48.0 & 45.0 & 45.3 & 43.3 \\
\hline $\begin{array}{l}\text { T2 UNA VEZ DIA/ } \\
\text { DIURNO }\end{array}$ & 6 & 32.3 & 48.0 & 33.0 & 36.7 & 27.3 \\
\hline $\begin{array}{l}\text { T3 UNA VEZ DIA/ } \\
\text { NOCHE }\end{array}$ & 6 & 33.7 & 27.0 & 30.3 & 38.3 & 38.7 \\
\hline $\begin{array}{l}\text { T4 UNA VEZ/ } \\
\text { SEMANA }\end{array}$ & 6 & 33.7 & 40.7 & 38.3 & 50.3 & 27.7 \\
\hline F (ANOVA) & & 2.83 & \multirow{2}{*}{\multicolumn{4}{|c|}{$\begin{array}{c}0.07>0.05 \text { Se acepta la hipótesis nula } \\
\text { que confirma que no existe diferencia } \\
\text { entre los grupos }\end{array}$}} \\
\hline $\begin{array}{c}\mathrm{P} \\
\text { SIGNIFICANCIA }\end{array}$ & & $\begin{array}{l}0.07 \\
0.05\end{array}$ & & & & \\
\hline
\end{tabular}

En la Tabla 5 se muestra que no existe diferencia significativa $(\mathrm{p}<0.05)$ entre los Monocitos de la fórmula leucocitaria de las ratas en los diferentes grupos de evaluación. 
Tabla 7: Bandeados de la fórmula leucocitaria de Rattus Novergicus variedad Sprague Dawley sometidas a estrés provocada por depredador durante 4 semanas

\begin{tabular}{|c|c|c|c|c|c|c|}
\hline \multirow{2}{*}{ TRATAMIENTO } & \multirow{2}{*}{$\mathrm{N}^{0}$} & \multicolumn{5}{|c|}{$\begin{array}{l}\text { FÓRMULA LEUCOCITARIA } \\
\text { NEUTRÓFILOS BANDEADOS }\end{array}$} \\
\hline & & BASAL & $\begin{array}{c}\text { 1ra } \\
\text { semana }\end{array}$ & $\begin{array}{c}2 \mathrm{da} \\
\text { semana }\end{array}$ & $\begin{array}{c}\text { 3ra } \\
\text { semana }\end{array}$ & $\begin{array}{c}\text { 4ta } \\
\text { semana }\end{array}$ \\
\hline T1 CONTROL & 6 & 27.3 & 24.7 & 22.0 & 14.7 & 15.7 \\
\hline $\begin{array}{l}\text { T2 UNA VEZ DÍA/ } \\
\text { DIURNO }\end{array}$ & 6 & 35.0 & 8.3 & 5.3 & 6.3 & 6.0 \\
\hline $\begin{array}{l}\text { T3 UNA VEZ DÍA/ } \\
\text { NOCHE }\end{array}$ & 6 & 30.0 & 7.3 & 5.3 & 4.7 & 5.3 \\
\hline $\begin{array}{l}\text { T4 UNA VEZ/ } \\
\text { SEMANA }\end{array}$ & 6 & 28.3 & 9.3 & 5.7 & 9.0 & 5.7 \\
\hline F (ANOVA) & & 1.12 & \multirow{2}{*}{\multicolumn{4}{|c|}{$\begin{array}{l}0.00004<0.05 \text { Se acepta la hipótesis } \\
\text { alterna que confirma que existe al } \\
\text { menos un grupo distinto del resto de }\end{array}$}} \\
\hline $\mathrm{P}$ & & 0.00004 & & & & \\
\hline SIGNIFICANCIA & & 0.05 & & los dem & s grupos & \\
\hline
\end{tabular}

En la Tabla 6 se muestra que sí existe diferencia significativa $(p<0.05)$ entre los Neutrófilos Bandeados de la fórmula leucocitaria de las ratas en los diferentes grupos de evaluación. Al aplicar la prueba de post comparación de Tukey se encontró que los Neutrófilos Bandeados del Grupo Control varían sus cantidades de manera significativa $(>0.05)$ en el tiempo de los demás tratamientos, pero no existe diferencia significativa entre los tratamientos en el tiempo

Tabla 8: segmentados de la fórmula leucocitaria de Rattus Novergicus variedad Sprague Dawley sometidas a estrés provocada por depredador durante 4 semanas

\begin{tabular}{|c|c|c|c|c|c|c|}
\hline \multirow{2}{*}{ TRATAMIENTO } & \multirow{2}{*}{$\mathrm{N}^{\circ}$} & \multicolumn{5}{|c|}{$\begin{array}{c}\text { FÓRMULA LEUCOCITARIA } \\
\text { NEUTRÓFILOS SEGMENTADOS }\end{array}$} \\
\hline & & BASAL & $\begin{array}{c}\text { 1ra } \\
\text { semana }\end{array}$ & $\begin{array}{c}2 \mathrm{da} \\
\text { semana }\end{array}$ & $\begin{array}{c}\text { 3ra } \\
\text { semana }\end{array}$ & $\begin{array}{c}4 \text { ta } \\
\text { semana }\end{array}$ \\
\hline T1 CONTROL & 6 & 25.7 & 21.0 & 27.0 & 33.3 & 35.0 \\
\hline $\begin{array}{l}\text { T2 UNA VEZ DÍA/ } \\
\text { DIURNO }\end{array}$ & 6 & 28.3 & 23.7 & 13.0 & 14.3 & 31.3 \\
\hline $\begin{array}{l}\text { T3 UNA VEZ DÍA/ } \\
\text { NOCHE }\end{array}$ & 6 & 30.7 & 30.0 & 18.7 & 8.0 & 11.7 \\
\hline $\begin{array}{l}\text { T4 UNA VEZ/ } \\
\text { SEMANA }\end{array}$ & 6 & 32.7 & 21.0 & 20.0 & 19.3 & 22.7 \\
\hline F (ANOVA) & & 1.11 & \multirow{2}{*}{\multicolumn{4}{|c|}{$\begin{array}{c}0.37>0.05 \text { Se acepta la hipótesis nula } \\
\text { que confirma que no existe diferencia } \\
\text { entre los grupos }\end{array}$}} \\
\hline $\begin{array}{c}\mathrm{P} \\
\text { SIGNIFICANCIA }\end{array}$ & & $\begin{array}{l}0.37 \\
0.05\end{array}$ & & & & \\
\hline
\end{tabular}

En la Tabla 7 se muestra que no existe diferencia significativa $(p<0.05)$ entre los Neutrófilos Segmentados de la fórmula leucocitaria de las ratas en los diferentes grupos de evaluación.
Comparacion de promedios de los difrentes grupos de la fórmula leucocitaria de Rattus Novergicus variedad Sprague Dawley sometidas a estrés provocada por depredador durante 4 semanas

Tabla 9: Comparación de los promedios de basófilos

\begin{tabular}{ccccc}
\hline \multirow{2}{*}{ TIPO CELULAR } & \multicolumn{4}{c}{ BASÓFILO } \\
\cline { 2 - 5 } & T1 & T2 & T3 & T4 \\
\hline BASAL & 0.0 & 0.0 & 0.0 & 0.0 \\
1ra Semana & 0.0 & 0.0 & 0.3 & 0.0 \\
2da Semana & 0.0 & 0.0 & 0.0 & 0.0 \\
3ra Semana & 0.0 & 0.0 & 0.0 & 0.0 \\
4ta Semana & 0.0 & 0.0 & 0.0 & 0.3 \\
\hline
\end{tabular}

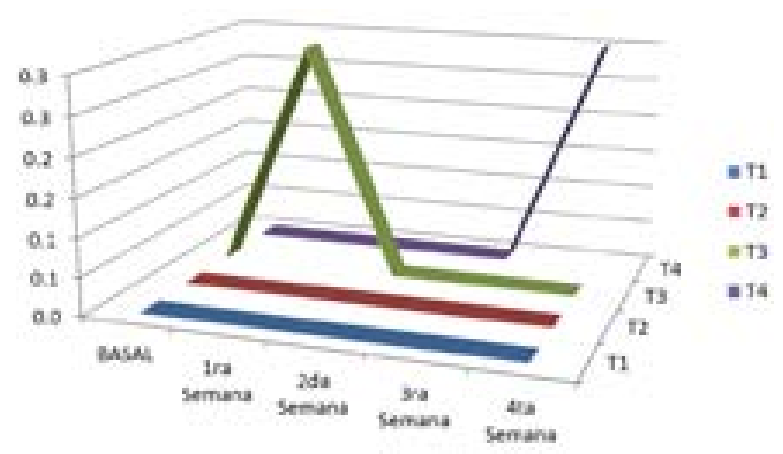

Gráfico 2: Comparación de los promedios de basófilos

Tabla 10: Comparación de los promedios de eosinófilos

\begin{tabular}{ccccc}
\hline \multirow{2}{*}{ TIPO CELULAR } & \multicolumn{4}{c}{ EOSINÓFILO } \\
\cline { 2 - 5 } & $\mathrm{T} 1$ & $\mathrm{~T} 2$ & $\mathrm{~T} 3$ & $\mathrm{~T} 4$ \\
\hline BASAL & 0.0 & 0.0 & 0.0 & 0.0 \\
1ra Semana & 0.3 & 1.3 & 1.3 & 1.3 \\
2da Semana & 0.3 & 1.3 & 6.3 & 0.7 \\
3ra Semana & 0.7 & 0.0 & 0.0 & 0.7 \\
4ta Semana & 0.3 & 1.3 & 4.3 & 0.3 \\
\hline
\end{tabular}

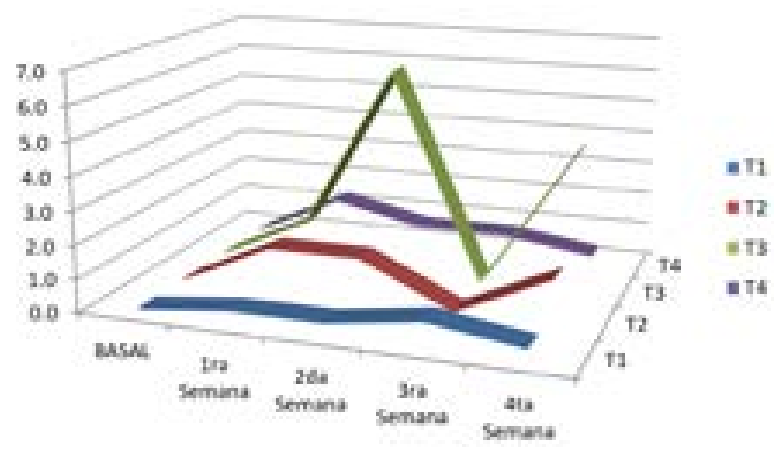

Gráfico 3: Comparación de los promedios de Eosinófilos 
Tabla 11: Comparación de los promedios de monocitos

\begin{tabular}{ccccc}
\hline \multirow{2}{*}{ TIPO CELULAR } & \multicolumn{4}{c}{ MONOCITO } \\
\cline { 2 - 5 } & $\mathrm{T} 1$ & $\mathrm{~T} 2$ & $\mathrm{~T} 3$ & $\mathrm{~T} 4$ \\
\hline BASAL & 5.7 & 4.3 & 5.7 & 5.3 \\
1ra Semana & 6.0 & 18.3 & 34.3 & 27.7 \\
2da Semana & 5.7 & 47.3 & 39.3 & 35.3 \\
3ra Semana & 6.0 & 42.7 & 49.0 & 20.7 \\
4ta Semana & 5.7 & 34.0 & 40.0 & 43.3 \\
\hline
\end{tabular}



Gráfico 4: Comparación de los promedios de monocitos

Tabla 12: Comparación de los promedios de linfocitos

\begin{tabular}{ccccc}
\hline \multirow{2}{*}{ TIPO CELULAR } & \multicolumn{4}{c}{ LINFOCITOS } \\
\cline { 2 - 5 } & T1 & T2 & T3 & T4 \\
\hline BASAL & 41.3 & 32.3 & 33.7 & 33.7 \\
1ra Semana & 48.0 & 48.0 & 27.0 & 40.7 \\
2da Semana & 45.0 & 33.0 & 30.3 & 38.3 \\
3ra Semana & 45.3 & 36.7 & 38.3 & 50.3 \\
4ta Semana & 43.3 & 27.3 & 38.7 & 27.7 \\
\hline
\end{tabular}

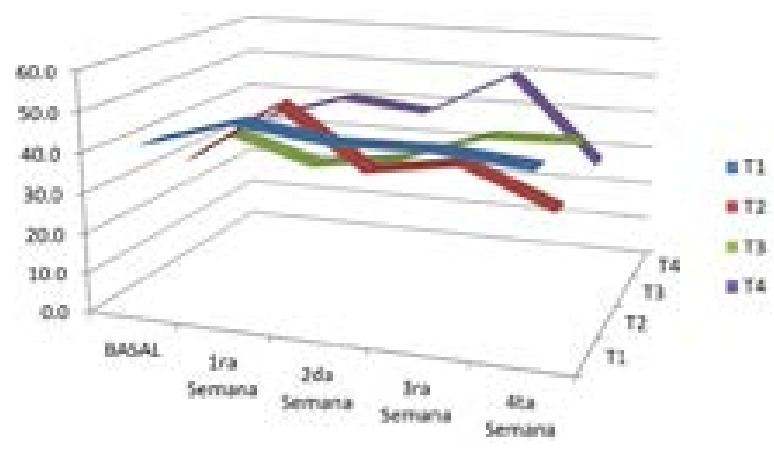

Gráfico 5: Comparación de los promedios de linfocitos
Tabla 13: Comparación de los promedios de neutrófilos bandeados

\begin{tabular}{ccccc}
\hline \multirow{2}{*}{ TIPO } & \multicolumn{4}{c}{ BANDEADOS } \\
\cline { 2 - 5 } CELULAR & T1 & T2 & T3 & T4 \\
\hline BASAL & 27.3 & 35.0 & 30.0 & 28.3 \\
1ra Semana & 24.7 & 8.3 & 7.3 & 9.3 \\
2da Semana & 22.0 & 5.3 & 5.3 & 5.7 \\
3ra Semana & 14.7 & 6.3 & 4.7 & 9.0 \\
4ta Semana & 15.7 & 6.0 & 5.3 & 5.7 \\
\hline
\end{tabular}

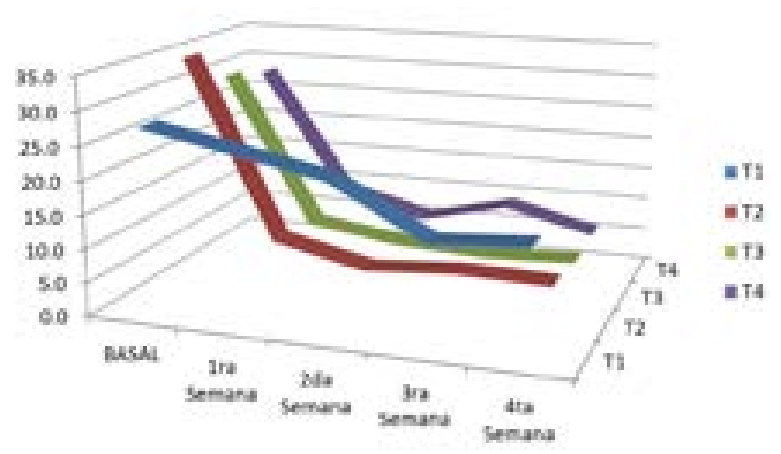

Gráfico 6: Comparación de los promedios de neutrófilos bandeados

Tabla 14: Comparación de los promedios de neutrófilos segmentados

\begin{tabular}{ccccc}
\hline \multirow{2}{*}{ TIPO } & \multicolumn{4}{c}{ SEGMENTADOS } \\
\cline { 2 - 5 } CELULAR & T1 & T2 & T3 & T4 \\
\hline BASAL & 25.7 & 28.3 & 30.7 & 32.7 \\
1ra Semana & 21.0 & 23.7 & 30.0 & 21.0 \\
2da Semana & 27.0 & 13.0 & 18.7 & 20.0 \\
3ra Semana & 33.3 & 14.3 & 8.0 & 19.3 \\
4ta Semana & 35.0 & 31.3 & 11.7 & 22.7 \\
\hline
\end{tabular}



Gráfico 7: Comparación de los promedios de neutrófilos segmentados 
Efecto del estrés sobre el tejido nervioso de Rattus Novergicus variedad Sprague Dawley

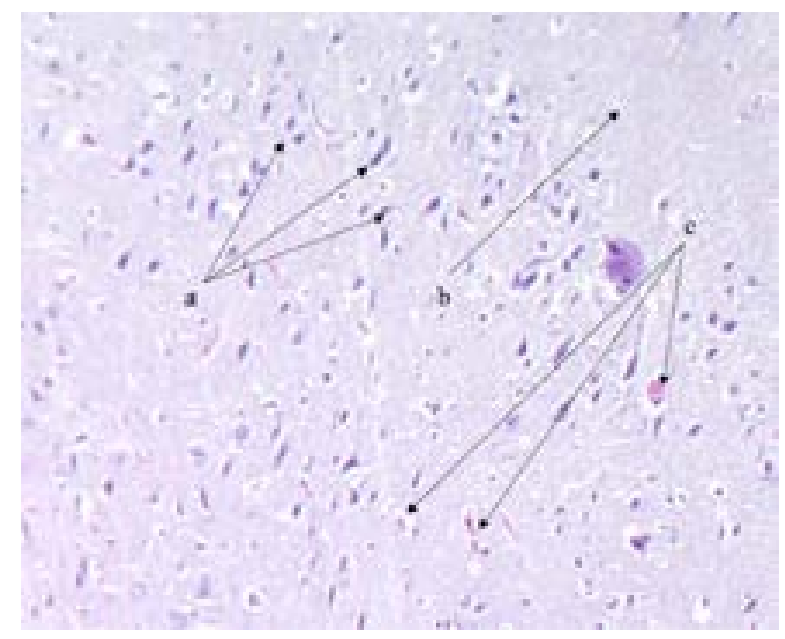

Foto 1: Estructura de corteza cerebral - tratamiento control en Rattus Novergicus variedad Sprague Dawley (Hematoxilina/ Eosina 400 x)

En esta microfotografía observamos la citoarquitectura normal de la corteza cerebral con características normales de ratas del grupo control (normal, sin lesión). Se observa tejido cerebral normal, tejido parenquimal con neuronas motoras (a), células gliales (b) y vasos sanguíneos intraparenquimales (c).
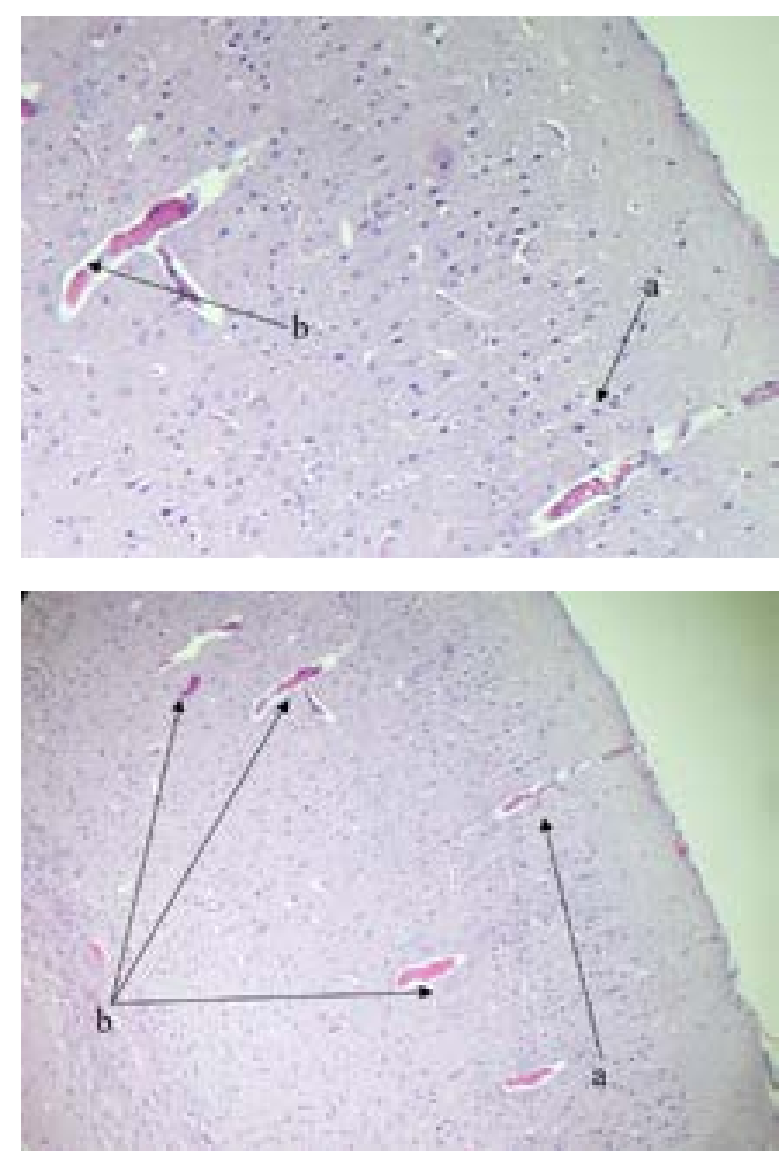

En esta microfotografía observamos una congestión vascular leve en la piamadre (a), congestión vascular y edema leve intraparenquimal (b).
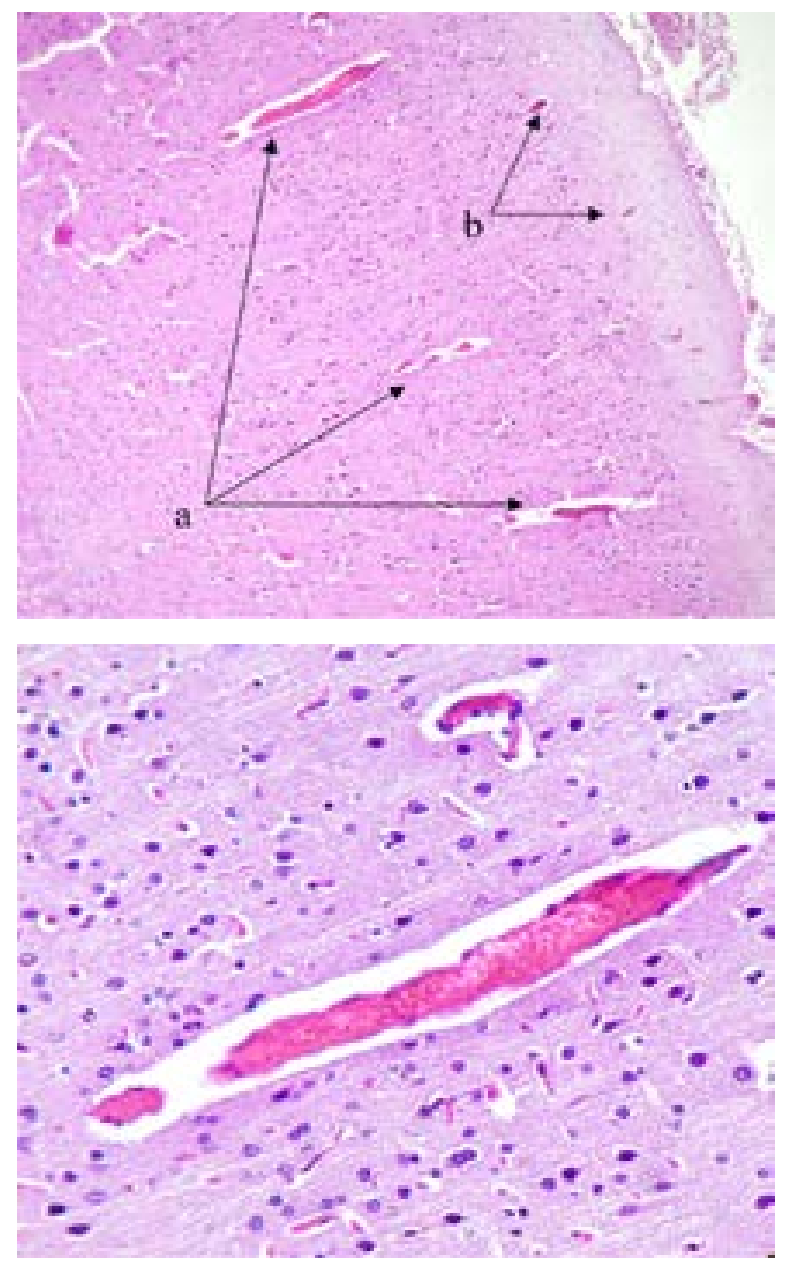

Foto 4 y 5: Estructura de corteza cerebral - tratamiento T3 (una vez por día/diurno) en Rattus Novergicus variedad Sprague Dawley (Hematoxilina/ Eosina 400 x)

En esta microfotografía observamos una congestión vascular moderada a severa intraparenquimal (a) y congestión vascular leve en la piamadre (b).

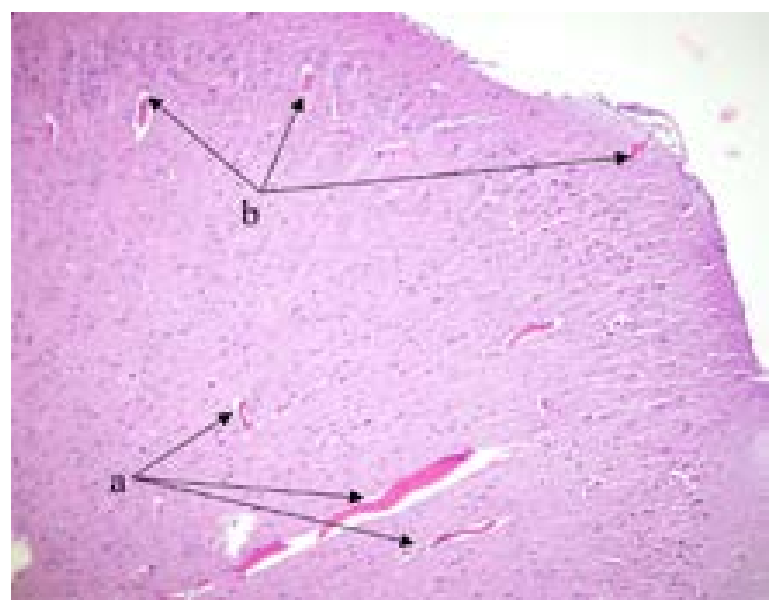

Foto 2 y 3: Estructura de corteza cerebral - tratamiento T2 (una vez por semana) en Rattus Novergicus variedad Sprague Dawley (Hematoxilina/ Eosina $400 \mathrm{x}$ ) 


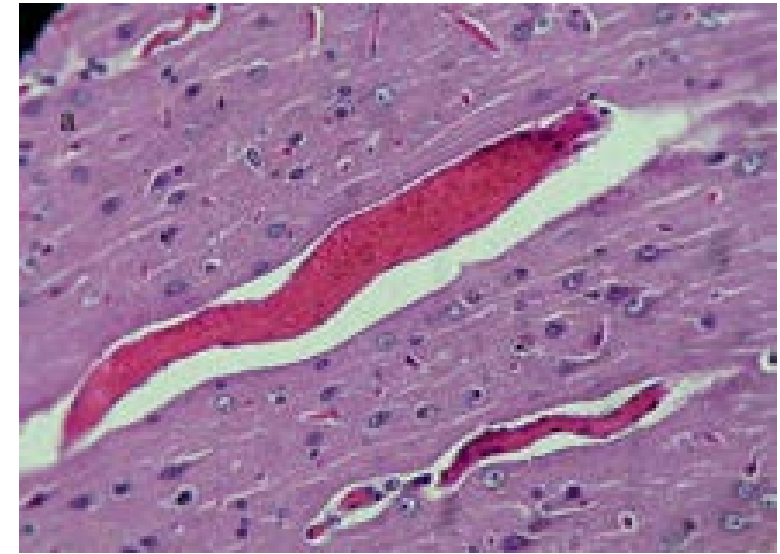

Foto 6 y 7: Estructura de corteza cerebral - tratamiento T4 (una vez por día/noche) en Rattus Novergicus variedad Sprague Dawley (Hematoxilina/ Eosina 400 x)

En esta microfotografía observamos una congestión vascular y edema severo intraparenquimal (a) y congestión vascular leve en la piamadre (b).

Efecto del estrés sobre el tejido cardiaco de Rattus Novergicus variedad Sprague Dawley
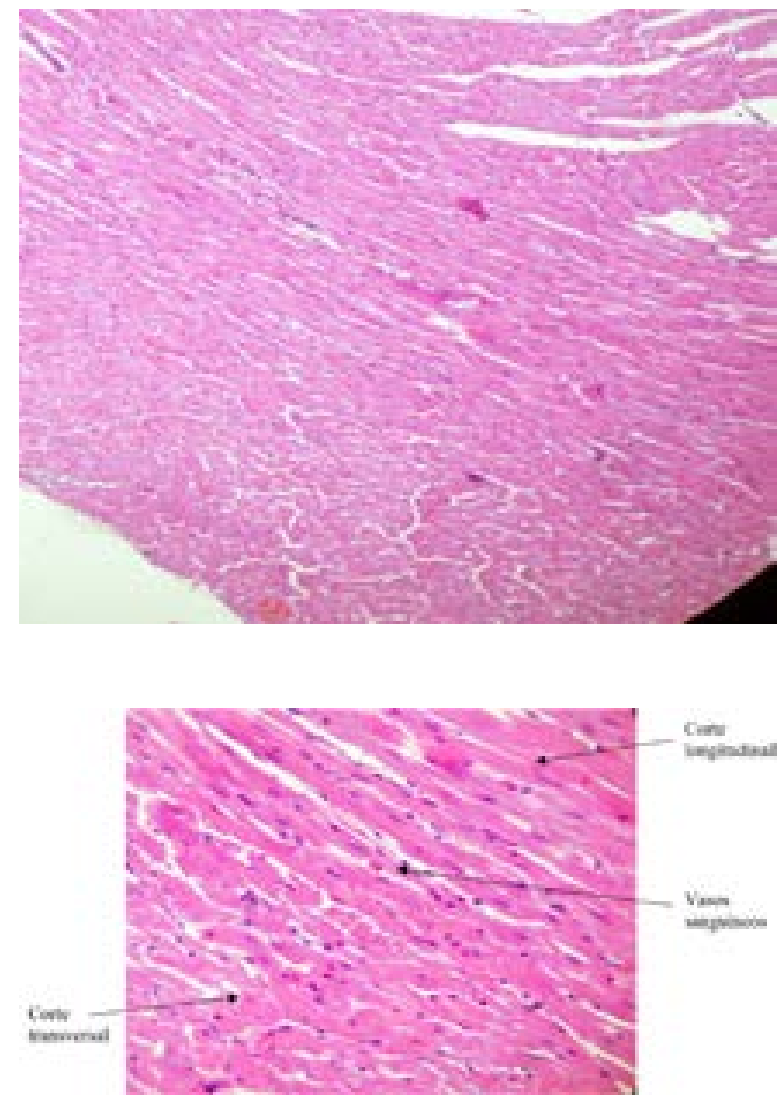

Foto 8 y 9: Estructura de tejido cardiaco - tratamiento control en Rattus Novergicus variedad Sprague Dawley (Hematoxilina/ Eosina $400 \mathrm{x}$ )

En esta microfotografía observamos las fibras musculares cardiacas en corte longitudinal y transversal. Los vasos sanguíneos y tejido intersticial normal.
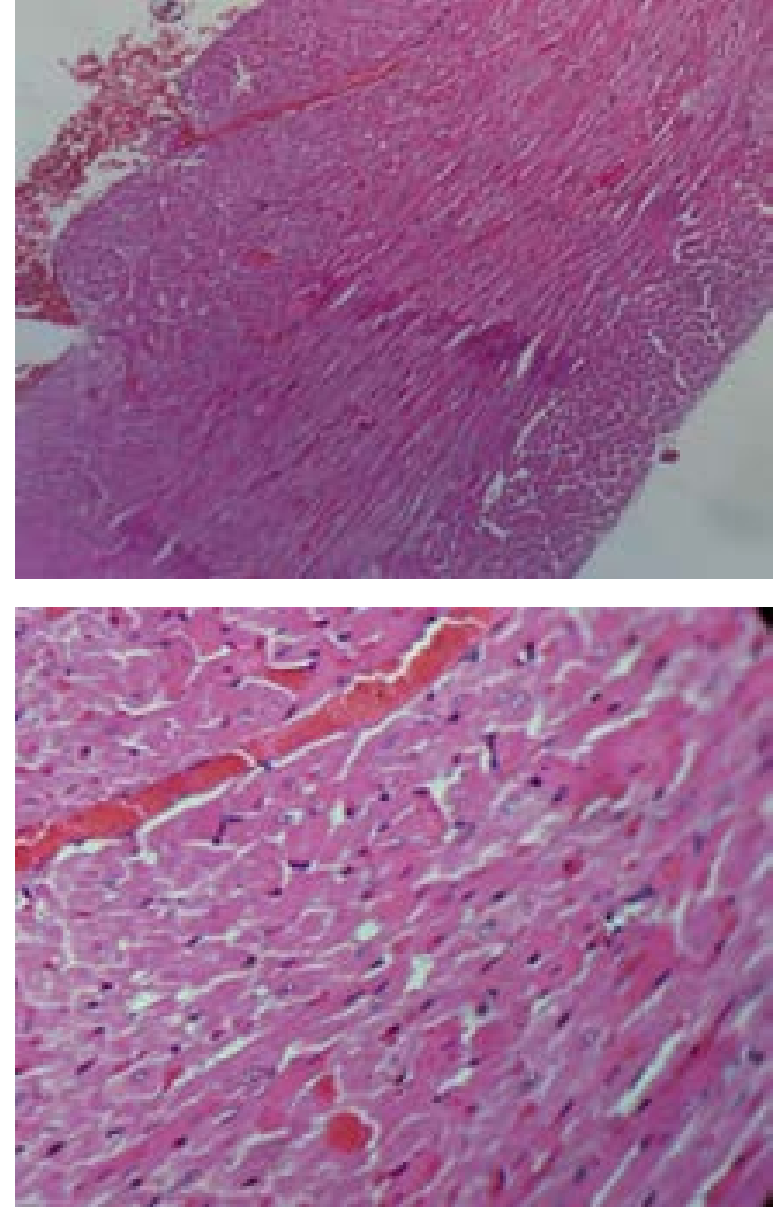

Foto 10 y 11: Estructura de tejido cardiaco - tratamiento $\mathrm{T} 1$ (una vez por semana) en Rattus Novergicus variedad Sprague Dawley (Hematoxilina/ Esina 40 x y 100x)

En esta microfotografía observamos congestión vascular moderada en el tejido cardiaco

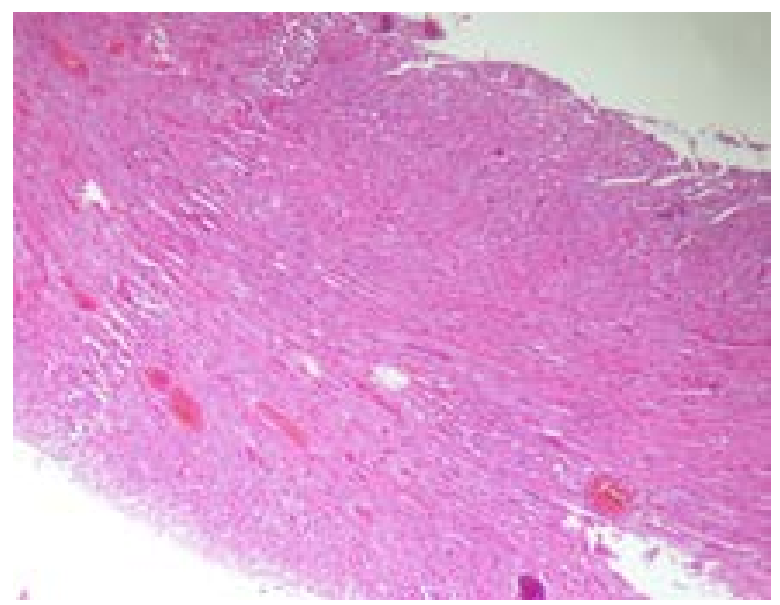




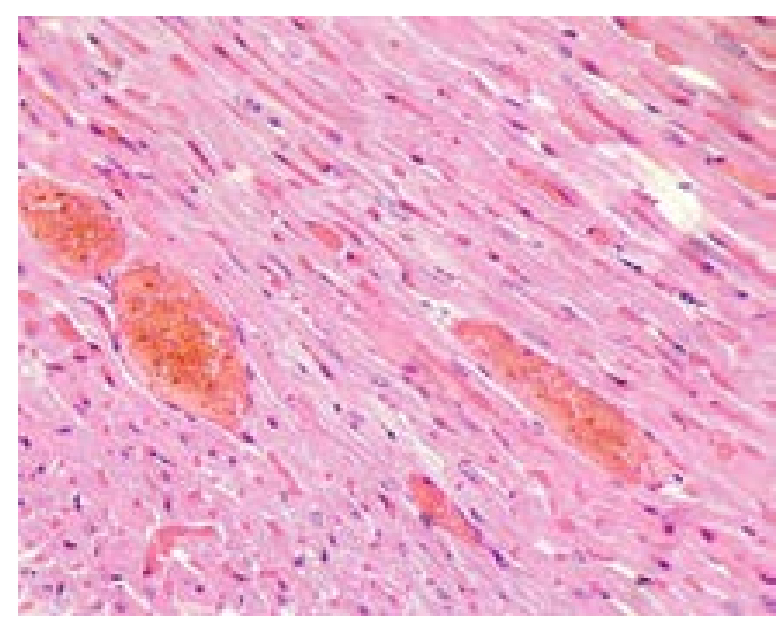

Foto 12 y 13: Estructura de tejido cardiaco - tratamiento T2 (una vez por día/diurno) en Rattus Novergicus variedad Sprague Dawley (Hematoxilina/ Eosina 40 x y 100x)

En esta microfotografía observamos congestión vascular moderada a severa en el tejido cardiaco.
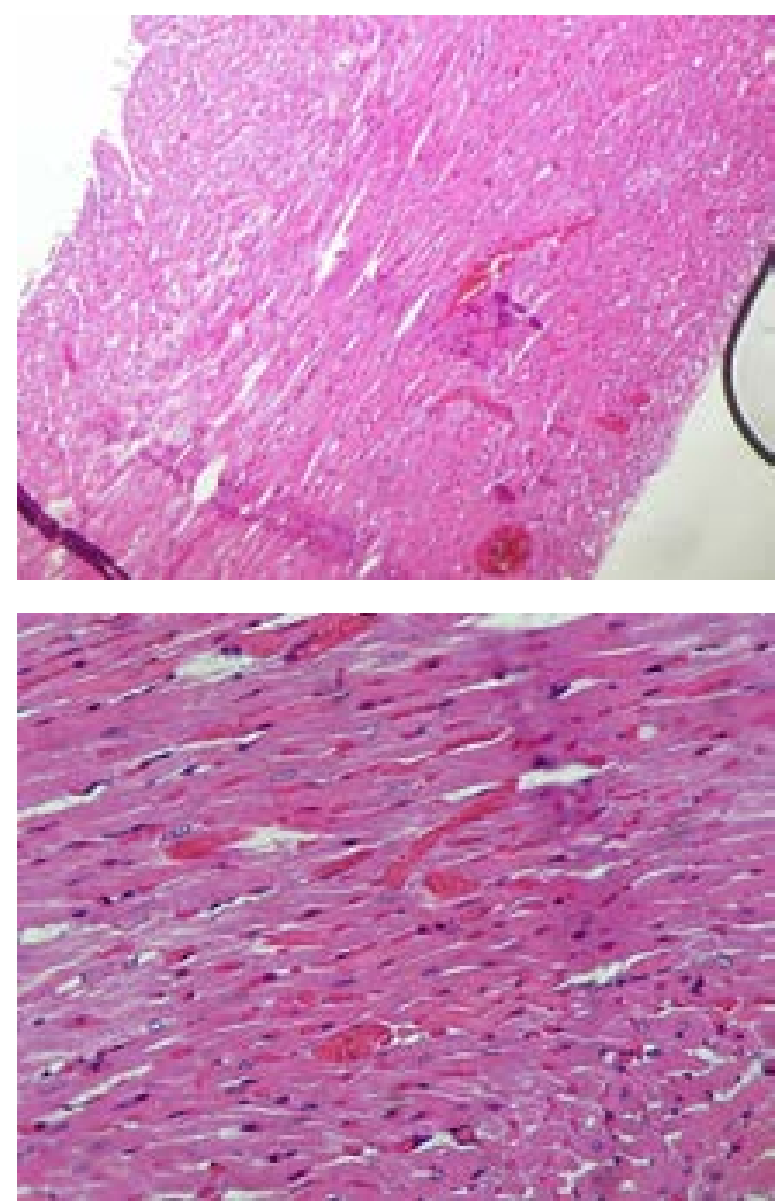

Foto 14 y15: Estructura de tejido cardiaco - tratamiento T3 (una vez por día/noche) en Rattus Novergicus variedad Sprague Dawley (Hematoxilina/ Eosina 40 x y 100x)

En esta microfotografía observamos congestión vascular moderada en el tejido cardiaco.

\section{DISCUSIÓN}

El estrés es una respuesta fisiológica de adaptación del organismo a situaciones de peligro, de desequilibrio homeostático y hasta disfunciones emocionales que se traducen en una serie de reacciones bioquímicas como respuesta de adaptación y retorno al equilibrio.

La población mundial está expuesta a múltiples situaciones estresantes. Cotidianamente, se han hecho muchísimos estudios acerca de los efectos del estrés sobre el tejido nervioso, especialmente en el hipotálamo, y sobre el tejido cardiaco enfocado en su rendimiento y las distintas patologías que puede provocar. También se han evaluado su efecto sobre el sistema inmunológico. Todos los estudios hechos son concluyentes que el estrés agudo o crónico tiene efectos dañinos sobre el sistema nervioso y sobre el tejido cardiaco, además provoca desconcertantes resultados respecto al sistema inmune. Aunque los mecanismos exacto mediante los cuales el estrés provoca dichas alteraciones orgánicas no está muy claro aún.

El presente trabajo consistió en examinar si la exposición al estrés puede provocar cambios o daños en los tejidos nervioso, cardiaco y las células blancas de la fórmula leucocitaria, se expusieron a 24 especímenes machos de la especie Rattus novergicus variedad Sprague Dawley a un tratamiento de estrés provocado por un depredador (Felis silvestris, sub especie catus - gato doméstico) por espacios controlados de 20 minutos por sesión, manteniendo todas las demás condiciones estables y similares para todas las ratas, durante 4 semanas.

Las respuestas al estrés fisiológicos se inician rápidamente y están diseñados para optimizar la movilización de los recursos y la restauración de la homeostasis.

Varios estudios demuestran la relación del estrés con las enfermedades coronarias de diversa índole aunque no se haya llegado a probar las vías exactas mediante las cuales se producen esos daños. Algunos estudios han demostrado también la relación del aumento de la enzima TGO (Transaminasa Glutámico Oxalacética) en personas con enfermedades cardiacas, debido a que su aumento se produce por el proceso necrótico del miocardio.

En el presente estudio se evidenció un aumento significativo de los niveles de TGO en sangre de los grupos T2 (20 min/día/ciclo diurno), T3 (20 min/día/ciclo noche) y T4 (20 $\mathrm{min} / \mathrm{sem} /$ ciclo diurno) con respecto de las medidas basales, de acuerdo a lo descrito por Robert B. Kalmansohn and Richard W. Kalmansohn en relación al daño del músculo cardiaco, y en relación a los resultados de las muestras de tejido cardiaco.

El estrés influye en la conformación de la fórmula leucocitaria, aumentando los eosinófilos, monocitos, linfocitos, Natural Killer, como los principales elementos de la serie blanca en ser afectados.

En el presente estudio, comprobamos el aumento, aunque no significativo, pero si en promedios de los eosinófilos, en el T3 ( $20 \mathrm{~min} /$ día/ciclo noche) de 0 a 2.4 ; lo mismo ocurrió con los monocitos, que experimentaron un aumento estadísticamente significativo (0.05) en comparación con los resultados basales, aunque no hubo diferencias significativas (0.05) entre los tratamientos, pero al examinar los promedios verificamos que el aumento se dio en el T3. Sin embargo se verificó que la cantidad de linfocitos, aunque no mostraron 
cambios estadísticamente significativos, al verificar sus promedios notamos que disminuyen ligeramente, y es más evidente en el T3, resultado contradictorio con lo descrito en la bibliografía.

Los basófilos no experimentaron un cambio significativo en este experimento, aunque no hay registro sobre como los afecta el estrés, y la bibliografía sobre las cantidades normales de basófilos en Rattus novergicus son concluyentes con lo descrito en el presente estudio.

La bibliografía no nos brinda información de cómo afecta el estrés a los neutrófilos, sin embargo nuestros resultados basales están de acuerdo con las cantidades descritas para esta especie. En el presente estudio comprobamos que el estrés afecta la cantidad de neutrófilos bandeados en sangre, demostrando una disminución estadísticamente significativa (0.05) en comparación con los valores basales, aunque no se demostró una diferencia estadísticamente significativa entre tratamientos. Al analizar los promedios observamos que el promedio más bajo sucede en el T3. Sin embargo los neutrófilos segmentados no evidenciaron un cambio estadísticamente significativo entre los tratamientos, pero al analizar los promedios notamos que sí hubo una disminución con respecto a los valores basales, y el promedio más bajo se dio en el T4.

En el presente estudio se ha verificado el daño histológico del tejido cerebral de los especímenes sometidos a estrés, siendo estos daños observados muy similares en los distintos tratamientos aplicados, evidenciándose la aparición edemas cerebrales y congestión vascular desde moderada a severa tanto en la corteza como en el tejido intraparenquimal. Siendo la inflamación un factor de riesgo importante en el deterioro cognitivo a largo plazo

La actividad cardiaca se ve modificada principalmente por los sistemas simpática y parasimpática, que son los que controlan el ritmo cardiaco de acuerdo a señales provenientes generalmente del sistema nervioso central. Varios estudios demuestran que existe una relación directa entre el estrés y la aparición de enfermedades coronarias 45 , enfermedades cardiacas isquémicas, arterioesclerosis, defectos aurículo ventriculares, infartos, arritmias, aterogénesis. Adicionalmente varios estudios demuestran la influencia pro inflamatoria de los sistemas nerviosos simpático y parasimpático sobre tejidos como el cardiaco.

En el presente estudio se ha verificado el daño histológico ocurrido en el tejido cardiaco de los especímenes expuestos a tratamientos por estrés, observado daños muy similares en los distintos tratamientos. Se ha evidenciado congestión vascular moderada a severa, como parte del proceso inflamatorio supuestamente inducido por la actividad conjunta del sistema nervioso simpático y una alteración selectiva del sistema inmunológico

\section{REFERENCIAS BIBLIOGRÁFICAS}

1. Montoro J., Mullol J., Jauregui I., Davila I., Ferrer M., Bartra J., Del Cuvillo A., Sastre J., Valero A. (2009). Stress and allergy. Journal Investig. Allergol Clin. Inmunol. 19: 40-47

2. Radley J, Kabbaj M., Jacobson L., Heydendael W., Yehuda R., Herman J. 5, (Set 2011). Stress risk factors and stress-related pathology: neuroplasticity, epigenetics and endophenotypes. Revista Strees. Vol 14 (5), pag. 481-497

3. Mucio R. y Daneri F.(2012). Biología del Comportamiento: Psicobiología del estrés. Buenos Aires, Argentina. Pag 4.

4. Munck A, Guyre PM, Holbrook NJ. (1984). Physiological functions of glucocorticoids in stress and their relation to pharmacological actions. Revista de Endocrinologia; Vol 5(1):25-44.

5. Keller-Wood ME, Dallman MF.(1984). Corticosteroid inhibition of ACTH secretion. Revista Endocrinology. Vol 5(1):1-24.

6. Attwood B., Bourgognon J., Patel S., Mucha M., Schiavon E., Skrzypiec A., Young K., Shiosaka S., Korostynski M., Piechota M., Przewłocki R., Pawlak R. (Mayo 2011). Neuropsin cleaves EphB2 in the amygdala to control anxiety. Revista Nature. May 19; 473(7347): $372-375$

7. Conrad C., Galea L., Kuroda Y., McEwen B. (Dic. 1996). Chronic stress impairs rat spatial memory on the Y maze, and this effect is blocked by tianeptine pretreatment. Revista Behavioral Neuroscience. Dic;110(6):1321-34.

8. López Mejía D., Valdovinos de Yahya A., Méndez-Díaz M., Mendoza-Fernández M., El Sistema Límbico y las Emociones: Empatía en Humanos y Primates. (JulioDiciembre, 2009). Psicología Iberoamericana Vol. 17, No. 2, pp. 60-69.

9. Extraido De La Pagina Web Http://Neurofisiologia10. Jimdo.Com/Sistema-Nervioso/Sistema-Limbico/

10. Extraido De La Pagina Web http://medmol.es/glosario/ hipocampo/

11. Cingolani H., Houssay B. (2009). Fisiología Humana de Houssay. 7ma Edición. Buenos Aires, Argentina. Editorial El Ateneo.

12. Sessle BJ, Adachi K, Avivi-Arber L, Lee J, Nishiura H, Yao D, Yoshino K. (Abril, 2007). Neuroplasticity of face primary motor cortex control of orofacial movements. Archives of Oral Biology. 2007 Abr;52(4):334-7.

13. He Y, Chen ZJ, Evans AC. Small-world anatomical networks in the human brain revealed by cortical thickness from MRI. Cerebral Cortex. 2007 Oct;17(10):2407-19.

14. Lin SK, Pan WH, Yeh PH. (2007). Prefrontal dopamine efflux during exposure to drug-associated contextual cues in rats with prior repeated methamphetamine. Brain Research Bulletin. 2007 Jan 9;71(4):365-71.

15. Gorchetchnikov A, Grossberg S. (2007). Space, time and learning in the hippocampus: how fine spatial and temporal scales are expanded into population codes for behavioral control. Neural Networks. 2007 Mar;20(2):182-93.

16. Andolina IM, Jones HE, Wang W, Sillito AM. (2007). Corticothalamic feedback enhances stimulus response precision in the visual system. Proceeding of the National Academy of Science of U S A. 2007 Jan 30;104(5):1685-90.

17. Johnson DL, Wiebe JS, Gold SM, Andreasen NC, Hichwa RD, Watkins GL, Boles Ponto LL. (1999). Cerebral blood flow and personality: a positron emission tomography study. The American Journal of Psychiatry. 1999 Feb;156(2):252-7. 
18. Wen Y, Li B, Han F, Wang E, Shi Y. (2012). Dysfunction of calcium/calmodulin/CaM kinase II $\alpha$ cascades in the medial prefrontal cortex in post-traumatic stress disorder. Molecular Medicine Report. 2012 Nov;6(5):1140-4. doi: 10.3892/mmr.2012.1022.

19. Kim JJ, Diamond DM. (2002). The stressed hippocampus, synaptic plasticity and lost memories. Nature Reviews Neuroscience. 2002 Jun;3(6):453-62.

20. McGaugh JL. (2004). The amygdala modulates the consolidation of memories of emotionally arousing experiences. Annual Review of Neuroscience. 2004;27:1-28.

21. Park CR, Campbell AM, Woodson JC, Smith TP, Fleshner M, Diamond DM. (2006). Permissive influence of stress in the expression of a U-shaped relationship between serum corticosterone levels and spatial memory errors in rats. Dose Response: a Publication of International Hormesis Society. 2006 Jun 20;4(1):55-74.

22. Sandi C, Woodson JC, Haynes VF, Park CR, Touyarot K, Lopez-Fernandez MA, Venero C, Diamond DM. (2005). Acute stress-induced impairment of spatial memory is associated with decreased expression of neural cell adhesion molecule in the hippocampus and prefrontal cortex. Biologycal Psychiatry. 2005 Apr 15;57(8):856-64.

23. Bremne JD, Vermetten E. (2001). Stress and development: behavioral and biological consequences. Development and Psychopathology. 2001 Summer;13(3):473-89.

24. Diamond DM, Park CR, Heman KL, Rose GM. (1999). Exposing rats to a predator impairs spatial working memory in the radial arm water maze. Hippocampus. 1999;9(5):542-52.

25. Diamond DM, Fleshner M, Ingersoll N, Rose GM. (1999). Psychological stress impairs spatial working memory: relevance to electrophysiological studies of hippocampal function. Behavioral Neuroscience. 1996 Aug;110(4):661-72.

26. Kim JJ, Koo JW, Lee HJ, Han JS. (2005). Amygdalar inactivation blocks stress-induced impairments in hippocampal long-term potentiation and spatial memory. The Journal of Neuroscience: The Official Journal of the Society for Neuroscience. 2005 Feb 9;25(6):1532-9.

27. Kim JJ, Lee HJ, Han JS, Packard MG. (2001). Amygdala is critical for stress-induced modulation of hippocampal long-term potentiation and learning. The Journal of Neuroscience: The Official Journal of the Society for Neuroscience. $2001 \mathrm{Jul}$ 15;21(14):5222-8.

28. Woodson JC, Macintosh D, Fleshner M, Diamond DM. (2003). Emotion-induced amnesia in rats: working memory-specific impairment, corticosterone-memory correlation, and fear versus arousal effects on memory. Learning \& Memory. 2003 Sep-Oct;10(5):326-36.

29. Park CR, Campbell AM, Diamond DM. (2001). Chronic psychosocial stress impairs learning and memory and increases sensitivity to yohimbine in adult rats. Biologycal Psychiatry. 2001 Dec 15;50(12):9941004.

30. Suvrathan A, Bennur S, Ghosh S, Tomar A, Anilkumar S, Chattarji S. (2013). Stress enhances fear by forming new synapses with greater capacity for long-term potentiation in the amygdala. Philosophical Transaction of the Royal Society of London: Series B Biological Science. 2013 Dec 2;369(1633):20130151.

31. Macdougall MJ, Howland JG. Acute stress and hippocampal output: exploring dorsal CA1 and subicular synaptic plasticity simultaneously in anesthetized rats. Physiological Report. 2013 Jul;1(2):e00035. doi: 10.1002/phy2.35.

32. Pagliaccio D, Luby JL, Bogdan R, Agrawal A, Gaffrey MS, Belden AC, Botteron KN, Harms MP, Barch DM. (2014). Stress-system genes and life stress predict cortisol levels and amygdala and hippocampal volumes in children. Neuropsychopharmacology. 2014 Apr;39(5):1245-53. doi: 10.1038/npp.2013.327.

33. Costa-Nunes J, Zubareva O, Araújo-Correia M, Valença A, Schroeter CA, Pawluski JL, Vignisse J, Steinbusch H, Hermes D, Phillipines M, Steinbusch HM, Strekalova T. Altered emotionality, hippocampusdependent performance and expression of NMDA receptor subunit mRNAs in chronically stressed mice. Stress, Amsterdan. Noruega. 2014 Jan;17(1):108-16. doi: 10.3109/10253890.2013.872619.

34. Dra Costa Gomes, Teresa Silva. (). Fisiología del sistema nervioso autónomo (SNA). Barcelona. España. Hospital del Mar - Esperanza. Extraída de la página web http://www.scartd.org/arxius/fisio_sna05.pdf.

35. Grassi G, Seravalle G, Cattaneo BM, Lanfranchi A, Vailati S, Giannattasio C, Del Bo A, Sala C, Bolla GB, Pozzi M. (1995). Sympathetic activation and loss of reflex sympathetic control in mild congestive heart failure. Circulation. 1995 Dec 1;92(11):3206-11. 